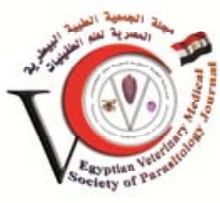

Original Article

\title{
The curative efficacy of Propolis on rabbits naturally infested
}

\section{with mite}

Dina M Metwally

Zagazig University, Faculty of

Veterinary Medicine

Parasitology Department,

King Saud University, Faculty of

Science, Zoology Department,

Riyadh, KSA

\begin{abstract}
:
The present study aims to evaluate the efficacy of Propolis (bee glue) ointment $10 \%$ and Ivermectin $(400 \mu \mathrm{g} / \mathrm{kg}, \mathrm{S} / \mathrm{C})$ as curative effect against rabbit mange (Psoroptes cuniculi and Sarcoptes scabier) infested on face, nose, ears, feet and body surface of rabbits. Thirty infested rabbits, 1-year-old, were examined during January to April 2015. They were divided into three main groups, control infected and untreated group, Propolis ointment $10 \%$ treated group and Ivermectin $(400 \mu \mathrm{g} / \mathrm{kg}, \mathrm{S} / \mathrm{C})$ treated group. Propolis ointment $10 \%$ yielded full recovery of the injuries and hair growth in the alopecic areas after applying once a day for 7-10 days on face, nose, feet and body surface and for 5-7 days on ears. From the second week of treatment, all examinations of skin scraping were negative for finding mange which may suggests the cidal effect of Propolis. In Ivermectin $(400 \mu \mathrm{g} / \mathrm{kg}, \mathrm{S} / \mathrm{C})$ treatment the rabbits returned to normal skin after an average of 20-25 days in face, nose and feet and 15-20 days on ears. On skin scraping, eggs were detected which suggests incomplete recovery as reinfection had occurred. The treatment of rabbit mange with propolis ointment $10 \%$ was effective, supporting the use of propolis as a hopeful natural alternative with no identified collateral effects.
\end{abstract}

Key words: Rabbit mange, Propolis, Ivermectin, full recovery

\section{INTRODUCTION}

Domestic rabbit (Oryctolagus cuniculus) are raised for meat, skin, wool, and as pets (Lebas et al., 1997). Parasitic infestation as mange is common in rabbit production, where widespread incidence has been approved by the mite Psoroptes cuniculi ( $P$. cuniculi), the most common cause of otitis and skin disease in domestic rabbits and Sarcoptes scabiei (burrowing mite), the highly contagious, pruritic skin condition. Burrowing mite is frequently found on the sparsely haired parts of the body as the face, ears and legs and is characterized by obvious pruritus, extensive pyoderma, severe alopecia and considerable weight loss (Soulsby, 1982) and (Aiello et al., 1982). Burrowing mite is of importance, they can affect, dogs and cats causing a transient itching dermatosis. The established treatment of mange includes external application of organophosphates, pyrethroid insecticides or amitraz (Fahmy, 1990). Two injections of Ivermectin (400 $\mu \mathrm{g} / \mathrm{kg}$, subcutaneously, at interval of 15 days (Ashmawy and Fahmy, 1987) along with supportive therapy showed appreciable improvement in clinical signs and restoration in biochemical parameters (Galdhar, 2015). This compound remains in the tissue long enough to kill the larva but it is non ovicidal (will not kill the egg) so, studies to develop new therapeutic approach to treat mange in rabbits have focused on using natural products. Amongst such products, propolis has recently seen increasing usage in medicine (Mugnaini, 2012). Propolis is made by bees and comprises about 50\% resinous components commonly polyphenols (Imhof, 2005). Its medical use has been documented. It has extensive pharmacological properties, including antibacterial, antifungal, antiviral, antiparasitic, anti-inflammatory, antioxidant, antiulcer, hepatoprotective, antitumor, immunomodulatory, healing and anesthetic (Bogdanov, 2012) and (DeCastro, 2001).

Our study aims to evaluate the activity of propolis against mite infestation in rabbits compared to the traditional drug, Ivermectin.

\section{MATERIALS AND MEthodS}

\section{Case history and clinical examination}

Thirty naturally infested rabbits, around 1-year-old, 2-2.4 $\mathrm{kg}$, were examined with crustaceous lesions on the head, neck, legs, ventral abdomen and perianal region. The case history revealed that the rabbits were housed in a wet and polluted environment and maintained on homemade food. First, the owner noticed yellow-grey scales in both ear pinnae (10 days before presentation) and sporadic 
scratching with front paws. Visual inspection exposed presence of crustaceous lesions on the ear pinnae and are surrounded by balding (alopecic) region (Fig 1), crustaceous lesions and yellowish discharge from both the limbs (Fig 2 a \& b) and wounds with secretions of watery stuff on body surface (Fig 3).

\section{Laboratory examination}

Infestation was identified grossly by lesions and confirmed by taking skin scraping samples smoothly with a scalpel blade dipped in mineral oil and they were microscopically examined for mobility, morphology and counting the mites (Lekimme, 2006; Bowman, 2009). The microscopic examination revealed $P$. cuniculi from the ear lesions (Fig 4 ) and Sarcoptes scabiei from the dorsal surface lesions of the body (Fig 5).

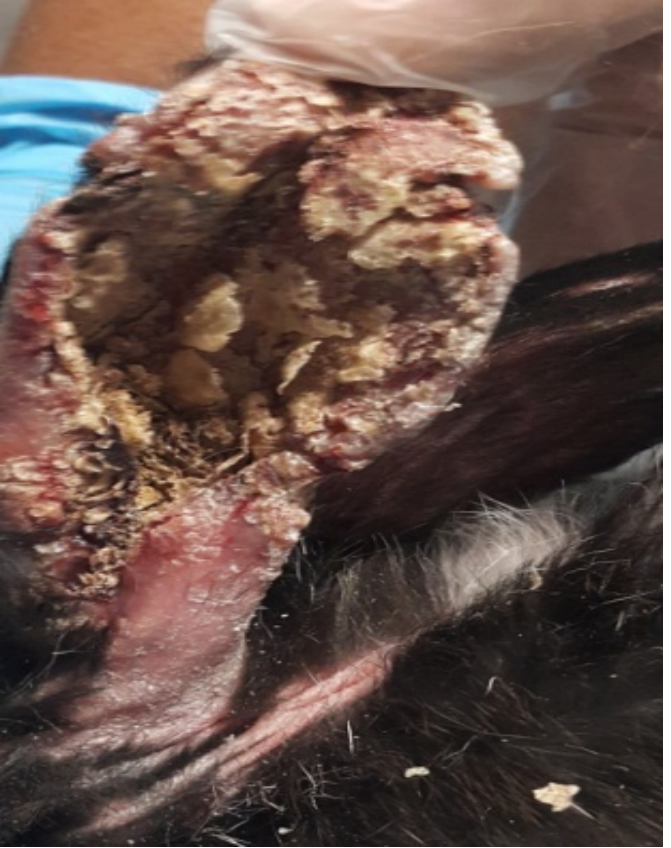

Figure 1: Clinical aspects of the ear before treatment (Psoroptes cuniculi).
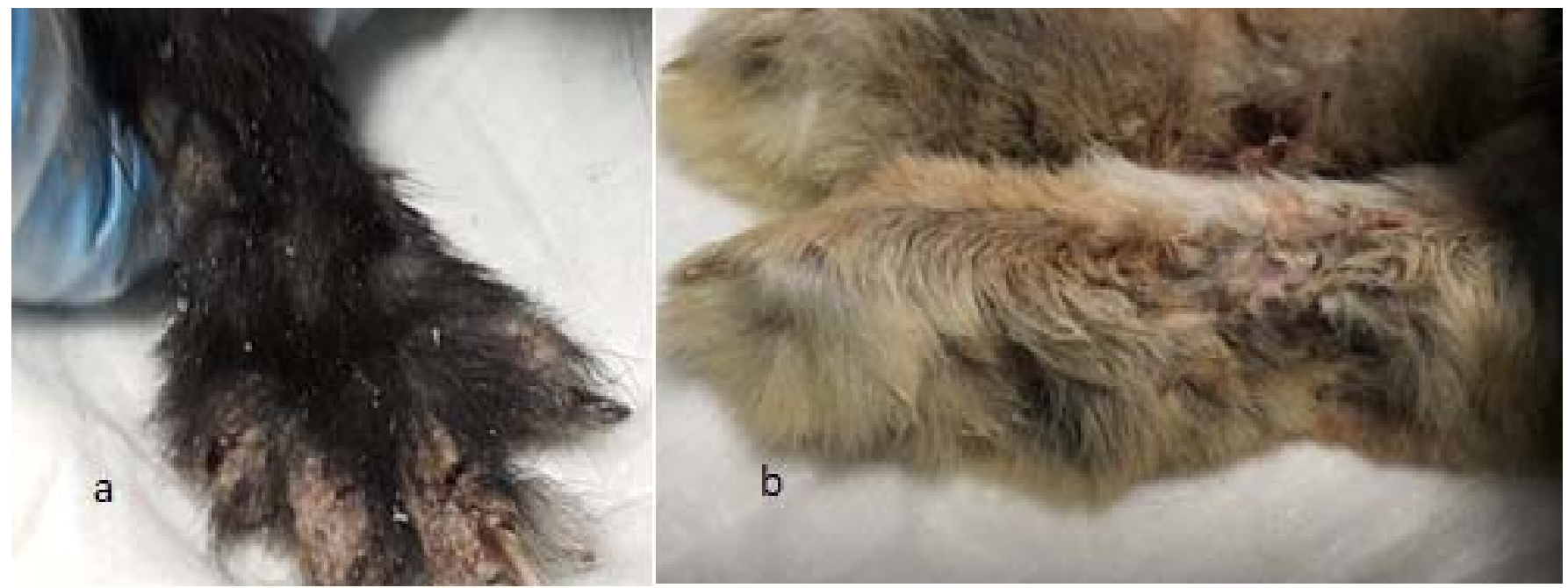

Figure 2: Clinical aspects of the legs before treatment (Sarcoptes scabiei).

a- Crustaceous lesions.

b- Yellowish discharge.

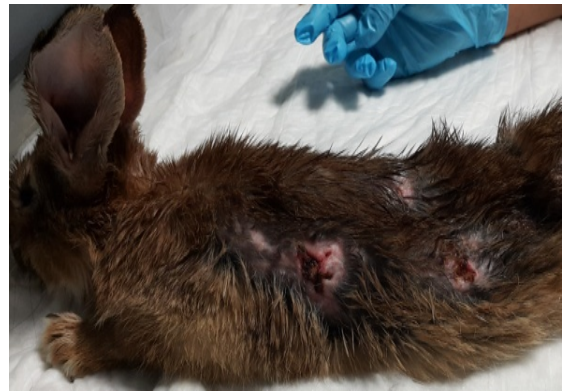

Figure 3: Clinical aspects of the body surface before treatment

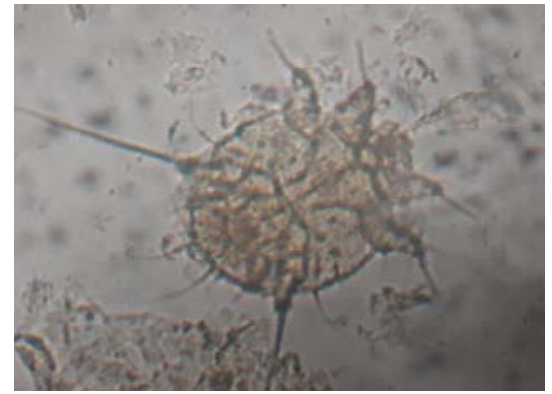

Figure 4: Adult Sarcoptes scabiei

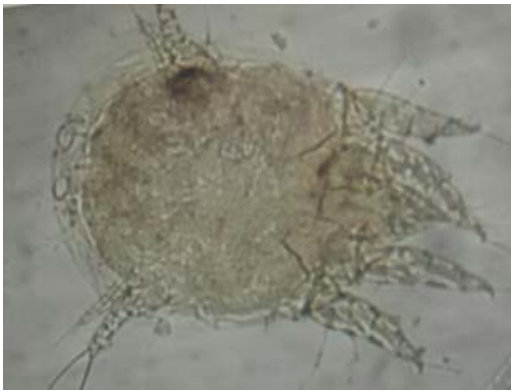

Figure 5: Adult Psoroptes cuniculi 


\section{Therapeutic management}

After identification of parasitic infestation, affected rabbits were divided into three groups with ten rabbits in each, group 1 served as control positive untreated group, group 2 received Propolis ointment 10\% treatment and group 3 received Ivermectin $(400 \mu \mathrm{g} / \mathrm{kg}, \mathrm{S} / \mathrm{C})$ two injections with two weeks interval (Galdhar, 2015).

The animals were kept in separate (to avoid any contact throughout the treatment period) wire bottomed cages in a room under standard condition of illumination with a 12 -hours light-dark cycle at $25 \pm 1^{\circ} \mathrm{C}$ for one week until the beginning of treatment. They were provided with tap water and balanced diet ad libitum.

This study was carried out in strict accordance with the recommendations in the Guide for the Care and Use of Laboratory Animals of the National Institutes of Health.The protocol was approved by the requirements of the local animal ethics committee of the University of SAU (IRB number: SAU-2015-Para -723/PI) of the joined work between College of Science (King Saud University) and Parasitology Department (Salman bin Abdulaziz University). The cages and all the equipment that rabbits could contact were also sprayed with acaricide spray to reduce the opportunity of re-infestation from the environment.

Propolis ointment $10 \%$ was made at laboratory using a propolis sample collected in the apiary of Almagmaa, Riyadh, Saudi Arabia. Ethanolic extract of propolis (EEP) was made by chopped up of $30 \mathrm{~g}$ propolis in $100 \mathrm{~mL} 70 \%$ ethanol for one week at room temperature then filtrated it and the extract was evaporated under vacuum at $50^{\circ} \mathrm{C}$. The propolis extract $(5 \mathrm{~g})$ was heated in a water bath with $30 \mathrm{~g}$ petroleum jelly (Vaseline) until melting and mixing. This mixture was used as the propolis ointment for application to the rabbits. The ointment was applied once daily to the lesions for ten days. The rabbits were supplied with a vitamin complex and commercial food. The cases were noted every week to reveal the alterations of lesions and this lasted for one month.

\section{RESULTS}

All rabbits were examined weekly from the first treatment. For (Group 1), the parasites were rapidly spread causing wounds with watery secretions, Secondary bacterial infection and some rabbits became lethargic and died within few days. For (Group 2) and (Group 3),
Table 1: Mean time on days for treatment of infested rabbits with mites by propolis ointment $10 \%$ and Ivermectin $(400 \mu \mathrm{g} / \mathrm{kg}, \mathrm{S} / \mathrm{C})$

\begin{tabular}{lccc}
\hline Treatment & \multicolumn{3}{c}{ Mean time of recovery (days) } \\
\cline { 2 - 4 } & $\begin{array}{c}\text { Face and } \\
\text { Nose } \\
\text { mange }\end{array}$ & $\begin{array}{c}\text { Ear } \\
\text { mange }\end{array}$ & $\begin{array}{c}\text { Feet and } \\
\text { body } \\
\text { mange }\end{array}$ \\
\hline Propolis oint $10 \%$ & $7-10$ & $5-7$ & $7-10$ \\
Ivermectin $(400 \mu \mathrm{g} /$ & $21-25$ & $15-20$ & $21-25$ \\
$\mathrm{~kg}, \mathrm{~S} / \mathrm{C})$ & & & \\
\hline
\end{tabular}

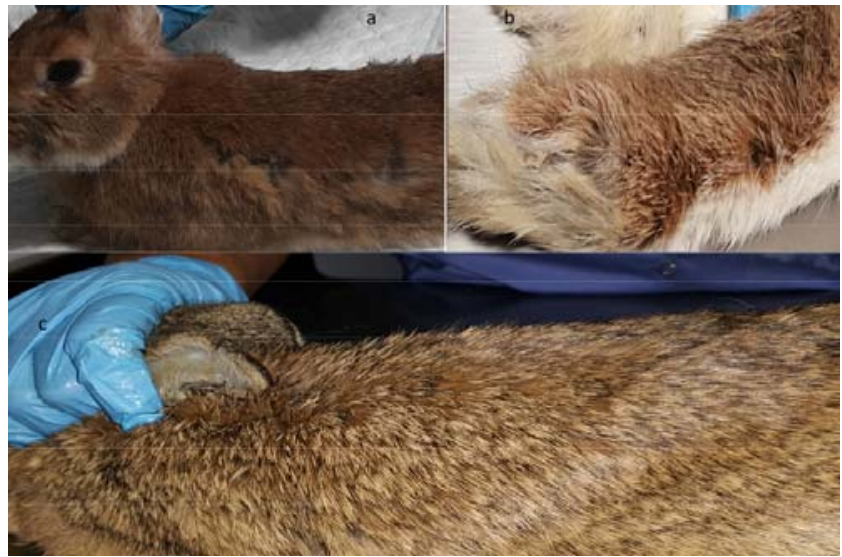

Figure 6: Improvement in:

a- body lesions on the $3^{\text {rd }}$ day Post treatment with propolis ointment $10 \%$

b- leg lesions on the $3^{\text {rd }}$ day Post treatment with propolis ointment $10 \%$

C- body lesions after the $10^{\text {th }}$ day Post treatment with propolis ointment $10 \%$

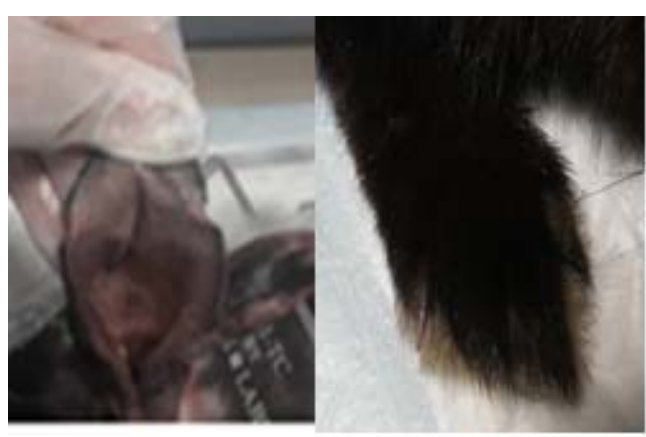

a

b

Figure 7: Improvement in ear (a) and foot (b) coat on $20^{\text {th }}$ and $25^{\text {th }}$ day respectively post treatment with ivermectin.

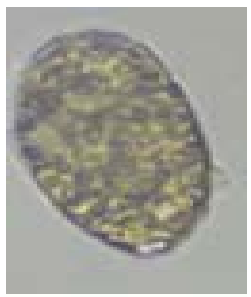

Figure 8: Sarcoptic mite egg 
reduction of all lesions and hair growth in the affected areas were observed. (Group 2) which was treated with propolis ointment $10 \%$ offered positive results from the $7^{\text {th }}-10^{\text {th }}$ day (Table 1 ) and the lesion resolution occurred progressively (Fig 6 a, b \& c) including significant reduction of pruritus and increased feed intake. Ivermectin $(400 \mu \mathrm{g} / \mathrm{kg}, \mathrm{S} / \mathrm{C}$ ) treated group (Group 3) showed healing of lesions and hair growth in the affected areas at the $20^{\text {th }}-25^{\text {th }}$ day of treatment (Table1) (Fig 7). The final resolution was after 25 days. The skin scrapings were negative for the presence of eggs, larvae and adult parasites in (Group 2), while eggs of Sarcoptic mite were detected in scraping from (Group 3) (Fig 8).

\section{Discussion}

Mange in rabbits is of economic concerns so, immediate effective treatment is important for the welfare and best production of rabbits. There are many acaricidal products as the systemically acting macrocyclic lactones (ivermectin, doramectin and moxidectin). The injectable macrocyclic lactones are quick and safe, cause less stress to the rabbit and don't require any special handling facilities (Curtis, 2004). Ivermectin $(400 \mu \mathrm{g} / \mathrm{kg}, \mathrm{S} / \mathrm{C}$ ) has been shown to be effective in the treatment of Notoedres mange infestation in pet rabbits after two injections at interval of 15 days with supportive therapy and on the $30^{\text {th }}$ day, no mite or their developmental stages were demonstrated on the examination of scrapings from the affected lesions which indicates complete recovery (Galdhar, 2015).

Similar results were obtained by Abd El-Aleem (2014), who reported the absence of mites ( $P$. cuniculi) in rabbits from the $7^{\text {th }}$ to $35^{\text {th }}$ day after subcutaneous administration of Ivermectin and Selamectin that killed any larvae hatching from eggs as well as preventing re-infection of mites off host .In our study, two injections of Ivermectin (400 $\mu \mathrm{g} / \mathrm{kg}, \mathrm{S} / \mathrm{C}$ ) with 2 weeks interval showed improvement within 21 days after the first injection. The injection was not completely effective against sarcoptic mange as the egg stage of sarcoptic mange was observed (not ovicidal) but, in case of Psoroptes cuniculi complete recovery was recorded.

The in vivo studies of antiparasitic activity of propolis against rabbit mange are scarce. However, the study performed by Abd El-Aal (2005) reported that the use of propolis ointment $10 \%$ for 3 successive days against rabbit mange (Sarcoptic and Psoroptic) resulted in complete reduction of clinical lesions from the third day of treatment and skin scrapings of treated parts after treatment were free from any stages of mite. In our study, we reported results similar to Abd El-Aal (2005).

The affected rabbits were treated with two injections of Ivermectin (400 $\mu \mathrm{g} / \mathrm{kg}, \mathrm{S} / \mathrm{C}$ ) with 15 days interval) along with supportive therapy. Our results persuade to develop a topical formula of propolis as a hopeful new therapy for the treatment of mange in rabbits, this formula has a wide anti scabies and anti-inflammatory effects of a natural and inexpensive product. The application of propolis was a highly effective treatment for rabbit mange, showing results better and faster than with the use of ivermectin.

\section{Acknowledgment}

The authors thank the deanship of scientific research at King Saud University for funding the work through the research group project No. RGPVPP-074.

\section{REFERENCES}

Abd El Aal A.M. (2005): Effect of propolis on mange in rabbits. Journal of Egyptian Veterinary Medical Association for Parasitology, 1(2):293-304.

Abd El-Aleem S.S. Desoky and Talaat M. El-Sheikh (2014): Study of Control against Mange Mite (Sarcoptes scabiei) in Naturally Infested Rabbits in Sohag Governorate, Egypt. Research Journal of Agriculture and Environmental Management, 3 (7): 315-319.

Aiello SE, Mays A. and Amstutz HE (1998): Rabbits. In: Aiello S.E. (ed.). Merck Veterinary Manual. New Jersey: Merck, Inc pp: 1386-96.

Ashmawy, K. and Fahmy, M.M. (1987): Acaricidal efficacy of Ivomec against Psoroptic and Sarcoptic mites infesting rabbits. J. Egypt. Vet. Med. Assoc. 47(1\&2): 315-319.

Bogdanov S. Propolis: Composition, Health, Medicine. (2012): A Review Bee Product Science, www.beehexagon.net, April 2015

Bowman DD (2009): Georgis' Parasitology for Veterinarians. $9^{\text {th }}$ ed. Saunders/Elsevier, St. Louis, Missouri.

Curtis C.F. (2004): Current trends in the treatment of Cheyletiella and mite infestations in dogs and cats. Veterinary Dermatology, 15:108-14.

De Castro S.L. (2001): Propolis: Biological and Pharmacological Activities Therapeutic Uses of This BeeProduct. Annual Review of Biomedical, 3: 49-83.

Fahmy, M. M. (1990): The efficacy of Licid against Psoroptic and Sarcoptic mange among rabbits. Proc. $2^{\text {nd }}$ Sc. Conf., Egypt. Vet. Poult. Assoc., 204-210

Galdhar, C.N., Khangal, P.S., Pawar, M.L., Rasal, T.D. \& Digraskar, S.U. (2015): Clinico-biochemical and therapeutic studies on notoedric mange in pet rabbits. Journal of Parasitic Diseases, 39(1):113-116. 
Imhof TM, Lipovac M, Kurz, Ch, Barta M, Verhoeven HC and Huber JC (2005): Propolis Solution for the Treatment of Chronic Vaginitis. International Journal of Gynecology and Obstetrics, 89: 127-132.

Lebas F, Coudert P, Rochambeau H. and Thebault RG. (1997): The Rabbit Husbandry, health and production. FAO Animal and Health Production . Series 21.
Lekimme M, Mignon B, Tombeux S, Focant C, Maréchal F, Losson B. (2006): In vitro entomopathogenic activity of Beauveria bassiana against Psoroptes spp. (Acari: Psoroptidae). Vet Parasitol. 139:196-202.

Mugnaini LA, Nardoni A, Pintoa L, Pistelli B, Leonardi MB and Pisseri F. (2012): In Vitro and in Vivo Antifungal Activity of Some Essential Oils against Feline Isolates of Microsporum canis. J Micol Med, 22:179-84.

Soulsby EJL (1982): Helminthes, Arthropods and Protozoa of Domesticated Animals, $7^{\text {th }}$ ed. London: Bailliere Tindall. pp. 482-6. 